\title{
Spontaneous symphysiotomy: rare case review
}

\section{Ankita Choudhary*, Rekha Jhakhar, Balgopal Singh Bhati}

Department of Obstetrics and Gynaecology, S. N. Medical College, Jodhpur, Rajasthan, India

Received: 28 May 2016

Revised: 17 June 2016

Accepted: 18 June 2016

\section{*Correspondence:}

Dr. Ankita Choudhary,

E-mail: ankitac06@gmail.com

Copyright: ( ) the author(s), publisher and licensee Medip Academy. This is an open-access article distributed under the terms of the Creative Commons Attribution Non-Commercial License, which permits unrestricted non-commercial use, distribution, and reproduction in any medium, provided the original work is properly cited.

\section{ABSTRACT}

We present here a rare case of spontaneous symphysiotomy. In the case patient came with post-partum hemorrhage with severe pain in groin region, on clinical and pelvic examination there was a gap in pelvic syphysis which further confirmed by pelvic X-ray.

Keywords: Symphysiotomy, Maternal morbidity, Urinary catheter

\section{INTRODUCTION}

Symphysiotomy is the surgical division of fibro cartilaginous syphysis pubis and its reinforcing ligament to enlarge the diameter and capacity of pelvis to facilitate the process of vaginal birth in cases of moderate cephalo pelvic disproportion which may be spontaneous or assisted.

\section{Role in delivery}

Cutting a patient's syphysis allows two halves of pelvis to separate by 2 to $2.5 \mathrm{~cm}$. This increases its diameter by 0.6 to $0.8 \mathrm{~cm}$ which is enough to overcome mild to moderate CPD (Figure 1 and 2).

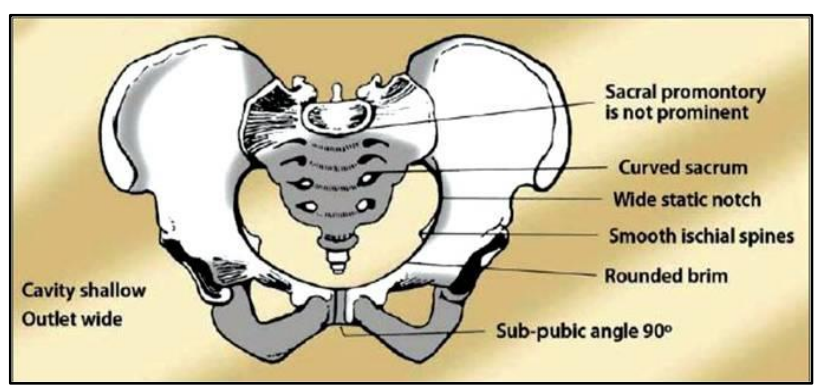

Figure 1: Normal anatomy of female pelvis.

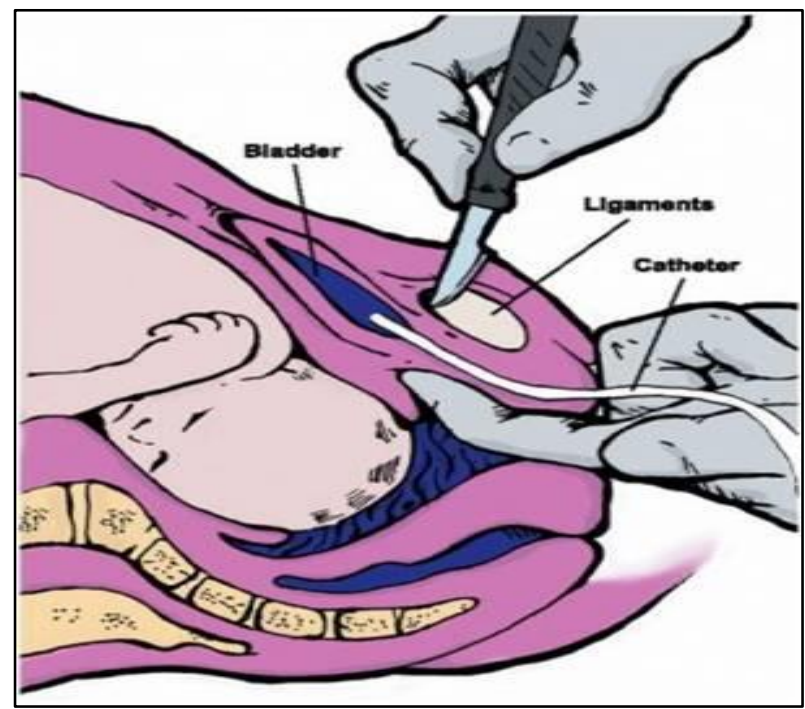

Figure 2: Procedure of symphysiotomy.

Symphysiotomy is indicated in following cases when safe caesarean section is unavailable

- $\quad$ Mild to moderate CPD

- Malpresentation like breech ${ }^{1,2}$

- Shoulder dystocia ${ }^{3}$ 


\section{CASE REPORT}

A patient 27 years old primipara was referred to umaid Hospital with complain of post-partum haemorrhage. Patient had delivered an alive MCH $3.75 \mathrm{~kg} .3$ hours back. Patient was referred in a state of hypovolemic shock with pulse rate of 170 beats per min and BP 100/60 $\mathrm{mmHg}$ along with haematuria. On P/A examination uterus was 16-18 weeks well contracted and a gap was felt between two pubic bones. X-ray pelvic region further confirmed this. Patient was given 3 units of blood transfusion and managed appropriately. After patient was stabilized, orthopaedic reference was done and patient was advised traction and immobilisation of lower limb with lumbosacral belt temporarily. She was also given intravenous metronidazole, cerufoxime and gentamicin for 24 hours, followed by oral cephalosporin and metronidazole for five days and indwelling catheter was maintained for five days. She was given thromboprophylaxis (Figure 3, 4 and 5).

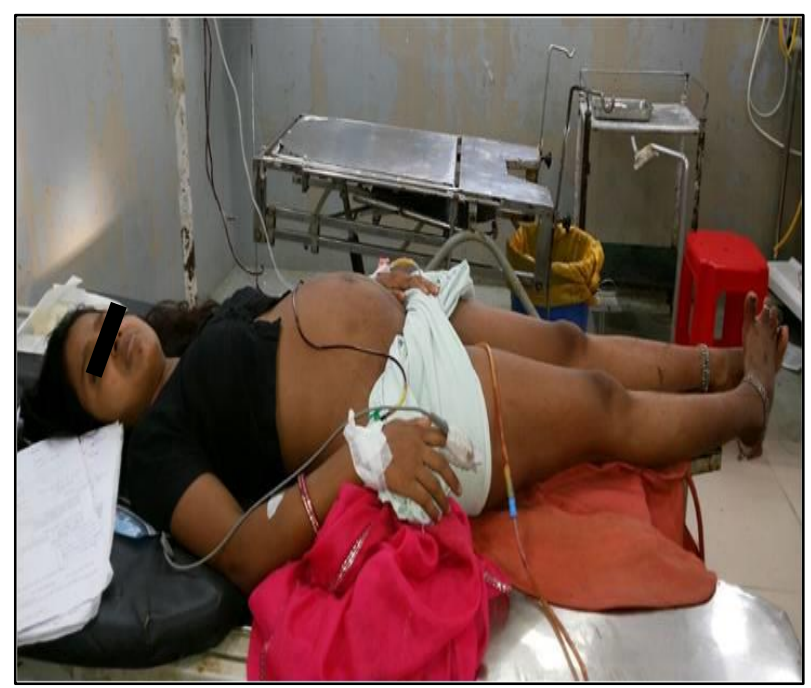

Figure 3: Patient with urinary cather and orthopaedic disability.

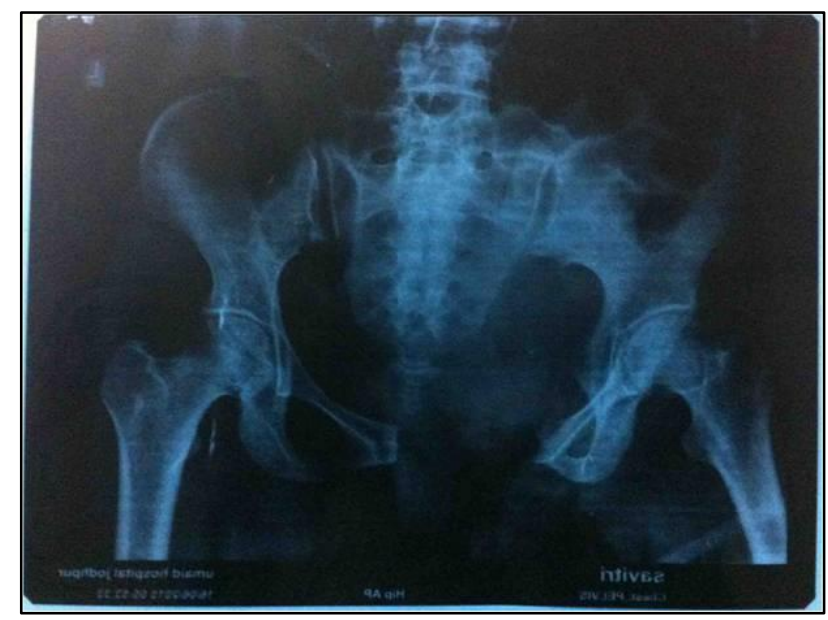

Figure 4: X-ray of pelvis with separation of pubic bones.

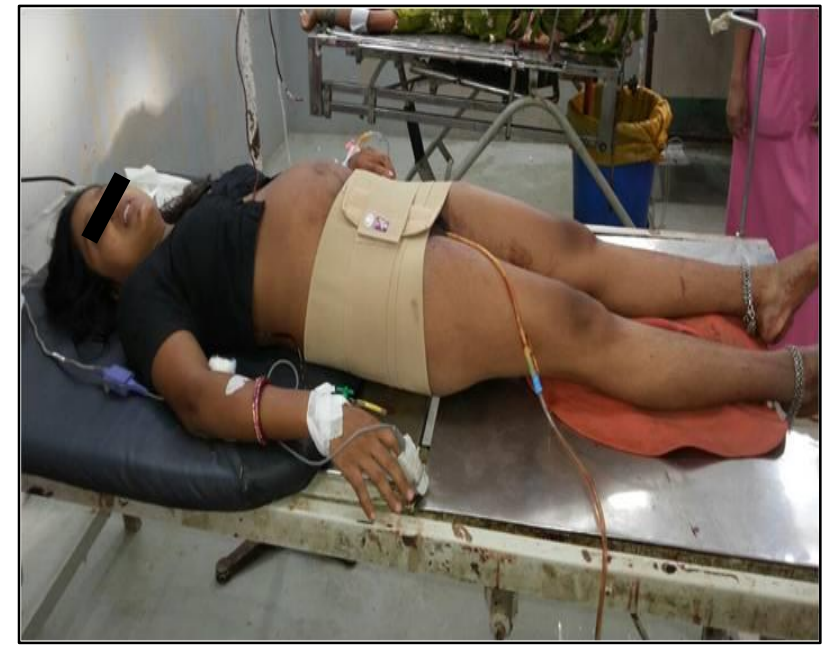

Figure 5: Patient after stabilisation.

\section{DISCUSSION}

Symphysiotomy has a very low maternal mortality, with three deaths reported in a series of 1752 symphysiotomies. ${ }^{4}$ In van Roosmalen's series, serious maternal morbidity included 30 vesicovaginal fistulae (1.7\%), 33 lesions of the anterior vaginal wall (1.9\%), 10 cases of osteitis pubis $(0.6 \%)$ and 32 women with long term walking difficulties or pain $(1.8 \%)$. More than one complication often occurred in one woman and the timing of incontinence suggested that 15 of the 30 fistulae were the result of pressure necrosis of the bladder neck by obstructed labour. Hart field reviewed published series of women followed for two years or more after symphysiotomy and concluded that major orthopedic disability occurs in $1-2 \%$ of women. ${ }^{5}$ Menticoglou reviewed 117 cases of symphysiotomy for the trapped after coming head of a breech presentation described in 34 reports between 1978 and 1987. ${ }^{1}$ A fetal survival rate of $80 \%$ was reported with little maternal morbidity.

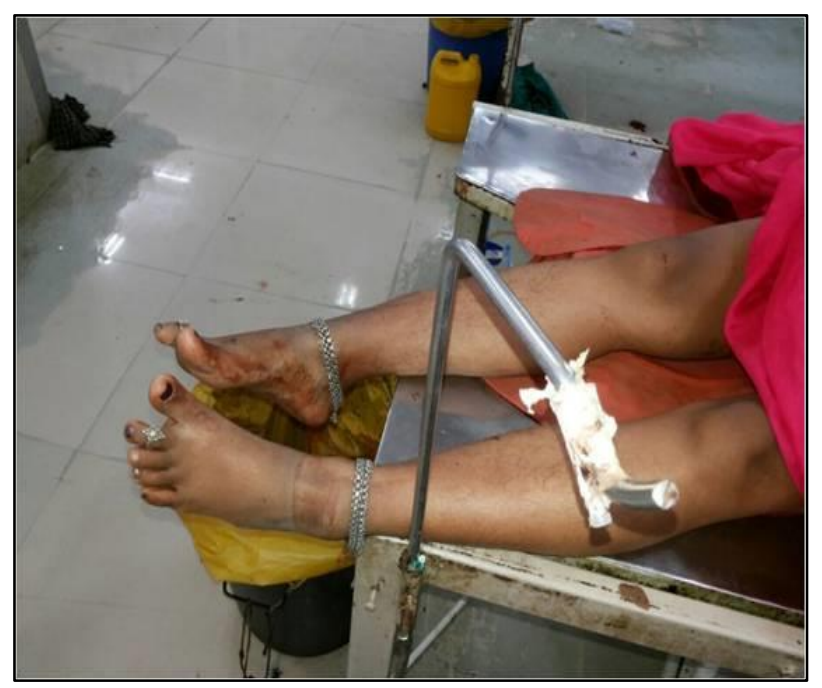

Figure 6: Patient with orthopaedic deformity in legs due to symphysiotomy. 


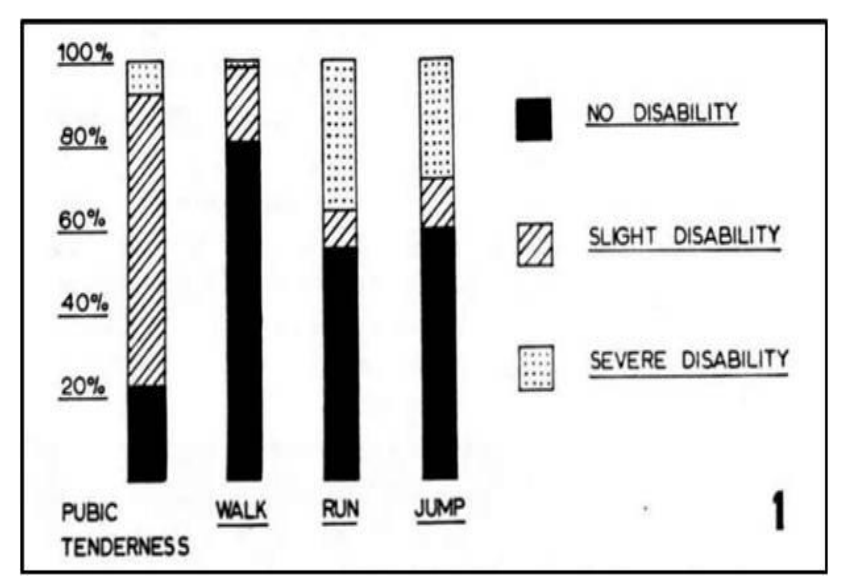

Figure 7: Different percent of disability due to symphysiotomy.

Page performed a prospective review of 27 symphysiotomy performed between 1992 and $1994 .{ }^{6}$ Five women had para urethral tears needing suturing and nine had oedema of the vulva majority of women (73\%) will have an uncomplicated vaginal delivery in a subsequent pregnancy. 4

Follow up patient was then referred to orthopedic department. They found patient's pelvis unstable. So patient was operated and fixation of pelvic bones was done with external fixator. Patient was advised bed rest for 1 Month (Figure 6 and 7).

\section{CONCLUSION}

This patient probably underwent spontaneous symphysiotomy as there was no history of any surgical procedure given by the patient. Because of availability of immediate and safe caesarean section, safe anaesthesia and complications of symphysiotomy doctors of today's world now prefer caesarean section over symphysiotomy. This patient was in great agony and pain when she came to us. With all resources and facilities available to us in this modern world, we cannot allow any mother to go through such hard labour.

\section{Funding: No funding sources \\ Conflict of interest: None declared \\ Ethical approval: Not required}

\section{REFERENCES}

1. Menticoglou SM. Symphysiotomy for the trapped aftercoming parts of the breech: a review of the literature and a plea for its use. Aust N Z J Obstet Gynaecol. 1990;30:1-9.

2. Spencer JAD. Symphysiotomy for vaginal breech delivery: two case reports. Br J Obstet Gynaecol. 1987;94:716-8.

3. Goodwin TM, Banks E, Millar L, Phelan J. Catastrophic shoulder dystocia and emergency symphysiotomy. Am J Obstet Gynecol. 1997;177:463-4.

4. Van Roosmalen J. Safe motherhood: cesarean section or symphysiotomy? Am J Obstet Gynecol. 1990;163:1-4.

5. Hartfield VJ. Late effects of symphysiotomy. Trop Doct. 1975;5:76-8.

6. Page GL. 27 Symphysiotomies. Trop Doct. 1999;29:248-9.

Cite this article as: Choudhary A, Jhakhar R, Bhati BS. Spontaneous symphysiotomy: rare case review. Int J Reprod Contracept Obstet Gynecol 2016;5:2485-7. 